\title{
Article \\ Comparison of Activation Methods for 3D-Printed Electrodes for Microbial Electrochemical Technologies
}

\author{
Raúl M. Alonso ${ }^{1}$, Isabel San Martín ${ }^{1}$ (D), Antonio Morán ${ }^{1}$ (D) and Adrián Escapa ${ }^{1,2, *(D)}$ \\ 1 Chemical and Environmental Bioprocess Engineering Group, Natural Resources Institute (IRENA), \\ Universidad de León, Avda. de Portugal 41, E-24009 Leon, Spain; ralog@unileon.es (R.M.A.); \\ msanb@unileon.es (I.S.M.); amorp@unileon.es (A.M.) \\ 2 Department of Electrical Engineering and Automatic Systems, Campus de Vegazana s/n, Universidad de \\ León, E-24071 Leon, Spain \\ * Correspondence: aescg@unileon.es
}

check for

updates

Citation: Alonso, R.M.; San Martín, I.; Morán, A.; Escapa, A. Comparison of Activation Methods for 3D-Printed Electrodes for Microbial

Electrochemical Technologies. Appl. Sci. 2022, 12, 275. https://doi.org/ 10.3390/app12010275

Academic Editors: Cristina

M. Cordas and Abdeltif Amrane

Received: 18 October 2021

Accepted: 22 December 2021

Published: 28 December 2021

Publisher's Note: MDPI stays neutral with regard to jurisdictional claims in published maps and institutional affiliations.

Copyright: (C) 2021 by the authors. Licensee MDPI, Basel, Switzerland. This article is an open access article distributed under the terms and conditions of the Creative Commons Attribution (CC BY) license (https:// creativecommons.org/licenses/by/ $4.0 /)$.

\begin{abstract}
Three-dimensional printing could provide flexibility in the design of a new generation of electrodes to be used in microbial electrochemical technologies (MET). In this work, we demonstrate the feasibility of using polylactic acid (PLA)/graphene-a common 3D-printing material-to build custom bioelectrodes. We also show that a suitable activation procedure is crucial to achieve an acceptable electrochemical performance (plain PLA/graphene bioanodes produce negligible amounts of current). Activation with acetone and dimethylformamide resulted in current densities similar to those typically observed in bioanodes built with more conventional materials (about $5 \mathrm{Am}^{-2}$ ). In addition, the electrodes thus activated favored the proliferation of electroactive bacteria.
\end{abstract}

Keywords: microbial electrochemical technologies; bioanode; exoelectrogen; graphene; 3D printing

\section{Introduction}

The advance of a multidisciplinary field like bioelectrochemistry runs parallel to that of other fields of knowledge, such as microbiology, electrochemistry, materials science or manufacturing engineering, in an interdependent manner [1]. Thus, the appearance of new materials, frequently referred to as nanomaterials, has opened new perspectives in the development of microbial electrochemical technologies (MET), which could contribute to overcoming global challenges in sustainable energy and waste management, as numerous publications have already shown [2-5]. Another technological breakthrough capable of evolving METs is additive manufacturing (AM) — commonly known as 3D printing-which has led to a paradigm shift in manufacturing engineering and has revealed potential in the development of functional MET prototypes [6]. The improvement of electrodes is a key aspect to promote the techno-economic feasibility of METs, as well as to broaden their field of application [7]. The search for electrodes that possess the desired characteristics (high conductivity, biocompatibility, ease of handling, and availability) is a challenge in the development of METs, even more so with the scaling up of these systems approaches on the horizon. A recently developed line of research is exploiting the advantages of polymer electrodes made by AM in electrochemical applications such as sensing [8,9] and energy storage $[10,11]$.

This study aimed at advancing towards the use AM for the development of bioelectrodes for METs. More specifically, we explored the suitability of using polylactic acid (PLA)/graphene-a common 3D-printing material - to build custom bioanodes. We also assessed the impacts that the activation of the electrodes (three different activation procedures are proposed) have on their (bio)-electrochemical performance. 


\section{Materials and Methods}

\subsection{Electrodes Manufacturing and Activation}

The electrodes were created using additive manufacturing (AM) with a fused deposition modelling (FDM) technique. The geometry of the electrodes, as shown in Figure 1, was designed to facilitate wiring and to facilitate subsequent experimentation. The printer used was a Prusa i3 (RepRap). In order to manufacture the electrodes, it was necessary to use a computer-assisted design (CAD) model and generate a standard triangle language (STL) file. Subsequently, the piece was manufactured by depositing a fused polymeric compound. In this study, graphene-loaded polylactic acid (PLA/graphene, Black Magic 3D, New York) was used as a printing material. We opted for PLA because it is one of the most popular materials used in desktop 3D printing (the graphene provides conductivity; volume conductivity: $\left.1.7 \mathrm{~S} \mathrm{~cm}^{-1}\right)$. The filament $(1.75 \mathrm{~mm}$ diameter) passed through a $0.4 \mathrm{~mm}$ diameter nozzle, the working temperature of which was $200^{\circ} \mathrm{C}$. Finally, the polymer was deposited layer by layer on the working surface of the machine. The working bed was tempered to $50{ }^{\circ} \mathrm{C}$ during the entire manufacturing process. The printing parameters for successful manufacture of the parts were as follows: (i) layer height of $0.2 \mathrm{~mm}$, (ii) a linear pattern with a $40 \%$ infill, and (iii) a printing speed of $2000 \mathrm{~mm} \cdot \mathrm{min}^{-1}$. Three activation procedures were essayed: electrochemical, chemical using dimethylformamide (DMF) as solvent, and chemical using acetone as solvent. The control electrode was gently cleaned with deionized water after manufacturing, but it underwent no activation procedure. Electrochemical activation was done in phosphate buffer solution ( $\mathrm{pH} 7$ ) by applying a cell potential of $2.5 \mathrm{~V}$ during $250 \mathrm{~s}$ in a two-electrode arrangement. The counter electrode was a platinum mesh (Goodfellow, PA, USA). DMF and acetone activation were performed by soaking the electrodes in the respective pure solvent (Sigma Aldrich, MO, USA) for $60 \mathrm{~s}$ and then removing the solvent by rinsing profusely with deionized water. Immersion times of more than $120 \mathrm{~s}$ in both DMF and acetone caused the destruction of the electrodes. The pre-treatment procedures were adapted from those proposed by Gusmão et al. [12], who pointed out DMF and acetone as suitable activation agents, and Browne et al. [13], who described the electrochemical activation procedure.
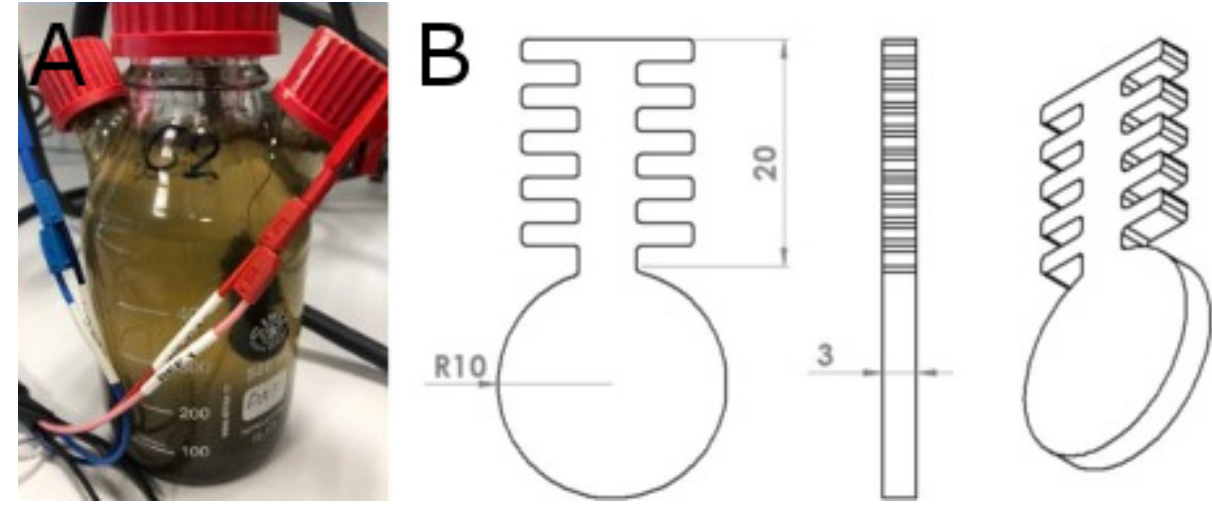

Figure 1. Bioelectrochemical reactor used in the experiments (A). Geometry of PLA electrodes, dimensions in $\mathrm{mm}(\mathbf{B})$.

\subsection{Electrochemical Characterisation Apparatus and Reagents}

The electrochemical behavior of the electrodes (control, electrochemical-activated, DMF-activated, and acetone-activated) was initially evaluated by cyclic voltammetry (CV) performed in a $5 \mathrm{mM} \mathrm{K}_{3} \mathrm{Fe}(\mathrm{CN})_{6}$ solution (support electrolyte $\mathrm{KCl} 0.1 \mathrm{M}$ ), with a scan rate of 1 to $20 \mathrm{mVs}^{-1}$. Electrochemical impedance spectroscopy (EIS) was recorded at an AC voltage perturbation amplitude of $10 \mathrm{mV}$ over the frequency region from $100 \mathrm{kHz}$ to $0.01 \mathrm{~Hz}$ in a potential region between 0 and $0.400 \mathrm{~V}$ vs. $\mathrm{Ag} / \mathrm{AgCl}(3.5 \mathrm{M})$ in order to get a deeper understanding of the pre-treatment effects in the material (frequencies less than $0.1 \mathrm{~Hz}$ were not used in EIS spectra interpretation since it is not possible to ensure pure diffusion- 
controlled conditions; see SI). All the electrochemical assays were performed using a VSP3 potentiostat (Biologic, France). The data analysis was carried out using the software associated with the equipment $\left(E C-\mathrm{Lab}^{\circledR} \mathrm{v} 11.33\right)$. The ohmic drop was compensated by a built-in method in the EC-Lab ${ }^{\circledR}$ software, based on resistance determination through EIS. The reference electrode (RE) was a commercial Ag/ $\mathrm{AgCl}$ (3.5 M) (Sigma Aldrich).

\subsection{Bioelectrochemical Tests}

The bioelectrochemical experiments were carried out in three single-chamber microbial electrolysis cells, named as Control, DMF, and Acetone, according to the anode pre-treatment applied. The reactor vessels consisted of modified $500 \mathrm{~mL}$ Duran ${ }^{\circledR}$ bottles, which allowed easy housing of the electrochemical apparatus. A three-electrode connection was used, establishing a working electrode (WE) potential of $+0.1 \mathrm{~V}$ with respect to the RE. The counter electrode was a $2 \times 2 \mathrm{~cm}$ square platinum mesh (Goodfellow, UK).

The electrodes were inoculated with river mud obtained from a local river mixed with growth medium in a 1:5 volume ratio. The growth medium composition per liter was: $0.87 \mathrm{~g}$ of $\mathrm{K}_{2} \mathrm{HPO}_{4}, 0.68 \mathrm{~g}$ of $\mathrm{KH}_{2} \mathrm{PO}_{4}, 0.25 \mathrm{~g}$ of $\mathrm{NH}_{4} \mathrm{CL}, 0.453 \mathrm{~g}$ of $\mathrm{MgCl}_{2} \cdot 6 \mathrm{H}_{2} \mathrm{O}, 0.1 \mathrm{~g}$ of KCl , $0.04 \mathrm{~g}$ of $\mathrm{CaCl}_{2} \cdot 2 \mathrm{H}_{2} \mathrm{O}, 10 \mathrm{~mL}$ of mineral solution, and $0.50 \mathrm{~g}$ of sodium acetate as the only carbon source. The mineral solution composition has been detailed by Marshall et al. [14].

After inoculation, the reactors were operated in fed-batch mode under controlled temperature conditions $\left(22 \pm 2{ }^{\circ} \mathrm{C}\right)$. A fresh medium solution with acetate $(10 \mathrm{mM}$ concentration) was refilled when the current dropped below $10 \%$ of the maximum value. The colonized electrodes were maintained for 60 days in the described growing conditions before starting the bioelectrochemical characterization tests.

\subsection{Microbial Community Analysis}

In order to study the microbial community attached to the electrodes, three samples were obtained from the electrodes (Acetone, DMF, and Control). Genomic DNA from these electrodes was extracted with the PowerSoil ${ }^{\circledR}$ DNA Isolation Kit (MoBio Laboratories Inc., Carlsbad, CA, USA), following the manufacturer's instructions. The entire DNA extract was used for the pyrosequencing of the 16S-rRNA gene-based massive library, targeting the eubacterial region V1-V3 16S-rRNA and performed at MR DNA (www.mrdnalab.com, accessed on 20 January 2021, Shallowater, TX, USA) utilizing MiSeq equipment (Illumina, San Diego, CT, USA). The primer set used was 27 Fmod (5'-AGRGTTTGATCMTGGCTCAG$3^{\prime}$ )/519 R modBio (5'-GTNTTACNGCGGCKGCTG-3'). Diluted DNA extracts were used as a template for PCR reactions. The obtained DNA reads were compiled in FASTq files for further bioinformatics processing. Trimming of the 16S-rRNA bar-coded sequences into libraries was carried out using QIIME software version 1.8.018. Quality filtering of the reads was performed at Q25 quality prior to grouping into operational taxonomic units (OTUs) at a $97 \%$ sequence homology cut-off. The following steps were performed using QIIME: a denoising procedure by using a denoiser algorithm19. Final OTUs were taxonomically classified using BLASTn against a database derived from the Ribosomal Database Project II (RDPII, http: / / rdp.cme.msu.edu, accessed on 20 January 2021) and the National Centre for Biotechnology Information (NCBI, www.ncbi.nlm.nih.gov accessed 20 January 2021).

\section{Results and Discussion}

\subsection{Electrodes Characterisation in Abiotic Conditions}

The aim of the abiotic characterization was to assess the impact of the different activation procedures on the electrochemical performance of the electrodes. Although the use of the $\left.\mathrm{Fe}(\mathrm{CN})_{6}\right]^{4-/ 3-}$ pair to evaluate the electrodes activity is not directly transferable to other electrochemical systems (e.g., bioelectrochemical systems), it provides an preliminary estimate of the effectiveness of the electrode $[2,15,16]$. The results from the CV tests (Figure 2) revealed a poor electrochemical performance of the electrochemically activated electrode compared to the DMF- and acetone-activated electrodes. In addition, and in accordance with Gusmão et al. [12], we observed that the activation procedure greatly 
affects the electrochemical properties of the material. Our results indicate that, based on the peak potential separation $(\Delta \mathrm{E})$ of the $\mathrm{CV}$ profiles (Figure 2), the acetone activation promotes a faster heterogeneous electron transfer rate than the DMF treatment $(\Delta \mathrm{E}=0.500 \mathrm{~V}$ against $0.758 \mathrm{~V})$, probably caused by differences in their electrocatalytic capacity.

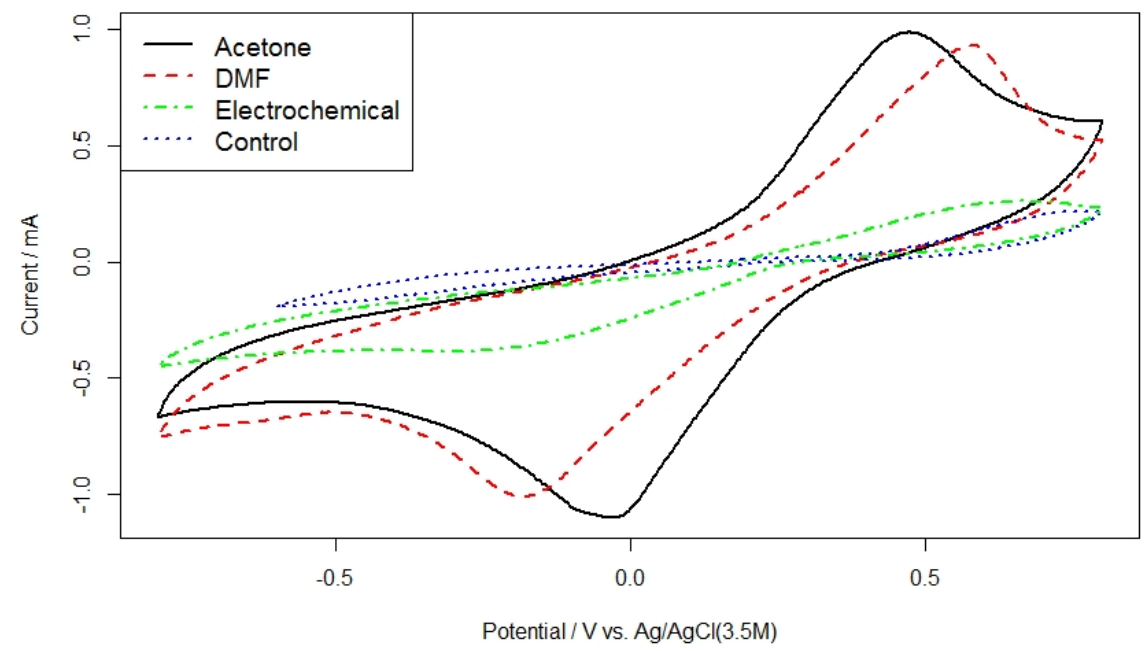

Figure 2. Cyclic voltammograms obtained for the different activation methods using the redox couple $\left.\mathrm{Fe}(\mathrm{CN})_{6}\right]^{4-/ 3-}$ at $2 \mathrm{mV} \cdot \mathrm{s}^{-1}$.

To gain a deeper insight on the impact of the activation method on the electrodes' performance, EIS analyses were carried out using the same redox pair $\left(\mathrm{Fe}(\mathrm{CN})_{6}\right]^{4-/ 3-}$ ), with a polarization potential of $0.250 \mathrm{~V}$ vs. $\mathrm{Ag} / \mathrm{AgCl}(3.5 \mathrm{M})$. The resulting Nyquist plots are shown in Figure 3. A characteristic semicircle-like pattern, attributable to the impedance associated with the charge transfer process, is observable for both the DMF and acetone electrodes in the high frequency region (see Figure 3 , inset), indicating that the oxidation reaction was kinetically controlled $\left(R_{c t}=313 \Omega\right.$ for DMF and $238 \Omega$ for acetone, where $R_{c t}$ is the charge transfer resistance). It is interesting to note that for the electrode activated with acetone, the "semicircle" region is depressed, which is probably indicative of pseudocapacitive behavior [17]. In contrast, the electrode treated with DMF exhibited behavior closer to the ideal capacitive behavior. The electrochemical-activated electrode showed much higher charge transfer impedance, indicating a poor electrochemical performance, which confirms the results obtained in the CV tests.

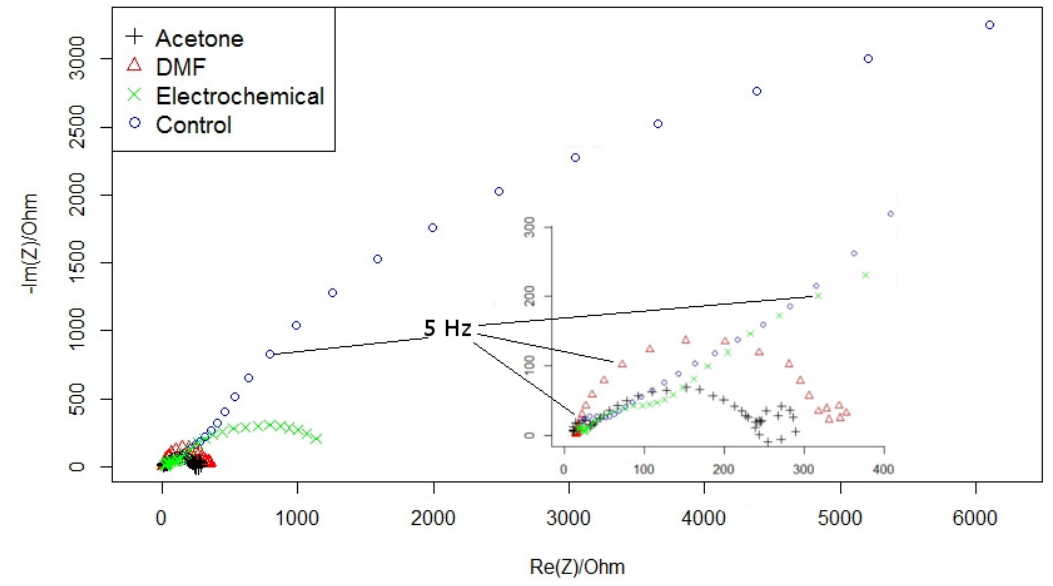

Figure 3. Nyquist plots from EIS experiments carried out at $0.250 \mathrm{~V}$ vs. $\mathrm{Ag} / \mathrm{AgCl}(3.5 \mathrm{M})$. The impedance spectra from different pre-treatments can be compared. The inset shows a detail from the high frequency region. The electrical equivalent circuits that fit the EIS data are shown in Figure S2 in the Supplementary Materials (the value of the electrical components is included in Tables S1 and S2). 


\subsection{Electrodes Characterisation in Biotic Conditions}

Following the abiotic tests, the electrodes were inoculated and operated according the procedure described in Section 2.3. Current started to increase right after inoculation in the DFM and acetone electrodes. A period of 60 days was allowed to favor the development of a mature electroactive biofilm, at the end of which the current profiles were fairly repeatable across successive cycles (see Figure S1 in the Supplementary Materials), and the averaged maximum current densities for the acetone and the DMF electrodes were 5.2 and $4.8 \mathrm{Am}^{-2}$, respectively. The electrochemically activated electrode failed to produce any current which, together with the poor performance it displayed in the abiotic test, led us to dismiss this electrode. Therefore, it was not subjected to further analyses in biotic conditions. Regarding the control electrode, although it produced some current, it was almost negligible compared to that of the DMF and acetone electrodes (see Figure S1 in the Supplementary Materials).

The bioelectrochemical performance of the electrodes was assessed by means of CV tests. The voltammograms recorded under non-turnover conditions (no substrate was available) showed the characteristic redox systems of a typical bioanode [18], with halfwave potentials at $-0.310 \mathrm{~V},-0.364 \mathrm{~V}$, and $-0.376 \mathrm{~V}$ (Figure 4 ), in accordance with the redox system associated to Geobacter sp. [19-21] and the mixed anodic consortia [19,22].

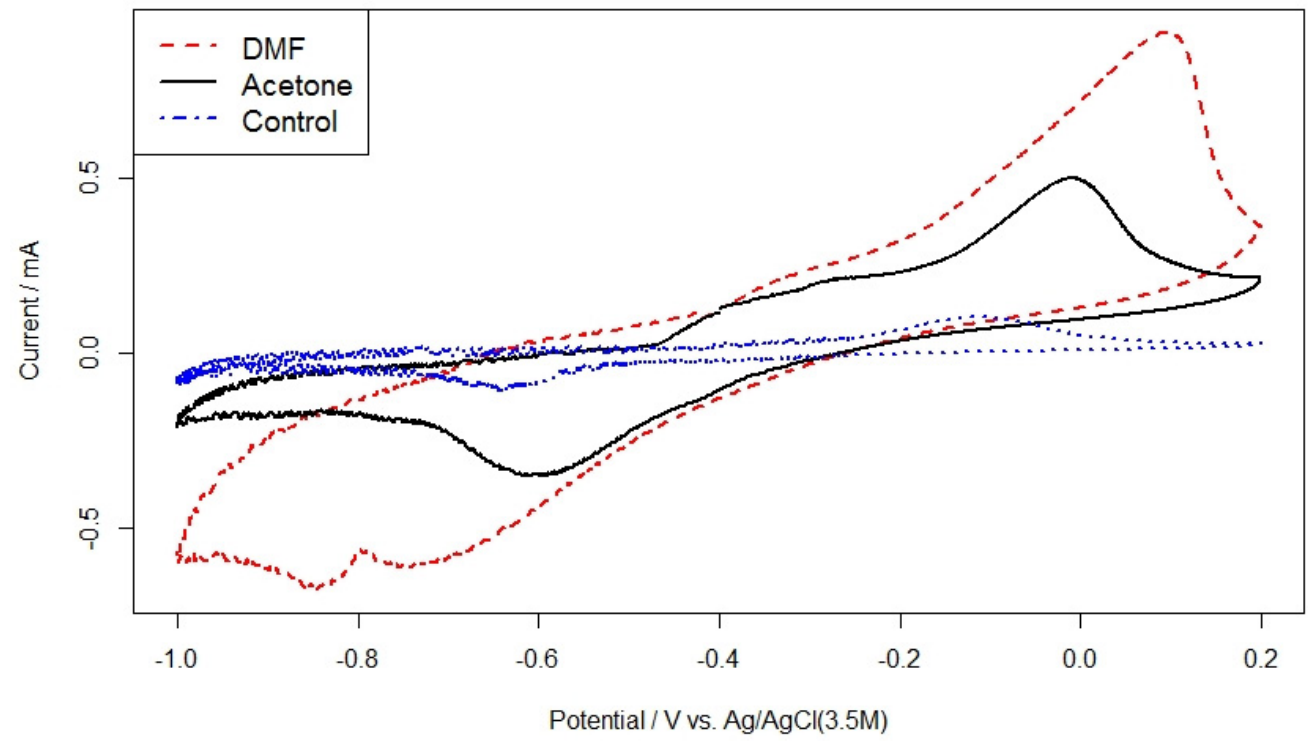

Figure 4. Cyclic voltammograms obtained under non-turnover conditions (scan rate: $0.1 \mathrm{mV} \cdot \mathrm{s}^{-1}$ ).

The results of the CV tests performed under turn-over conditions (33 mM acetate [23]) are shown in Figure 5. The current of the control cell was negligible (not included in the figure), compared to that of acetone and DMF. The voltammogram of the acetone electrode displayed a typical sigmoid-shaped profile, presenting a flat activation region $(-1.000$ to $-0.500 \mathrm{~V})$, a linear zone $(-0.500$ to $+0.035 \mathrm{~V})$, and an incipient "plateau", caused by the mass transfer limitation. In contrast to this, the DMF electrode showed a peak at $+0.244 \mathrm{~V}$ instead of the expected plateau region. This could be caused by a poor diffusion of either acetate or oxidation products (probably protons) through the biofilm [24]. This, together with the greater "thickness" of the voltammogram in the non-faradaic region $(-1.000$ to $-0.500 \mathrm{~V})$, suggests that the DMF activation generates an electrode/biofilm structure with a larger electrical capacity that could hinder the diffusion of species. 


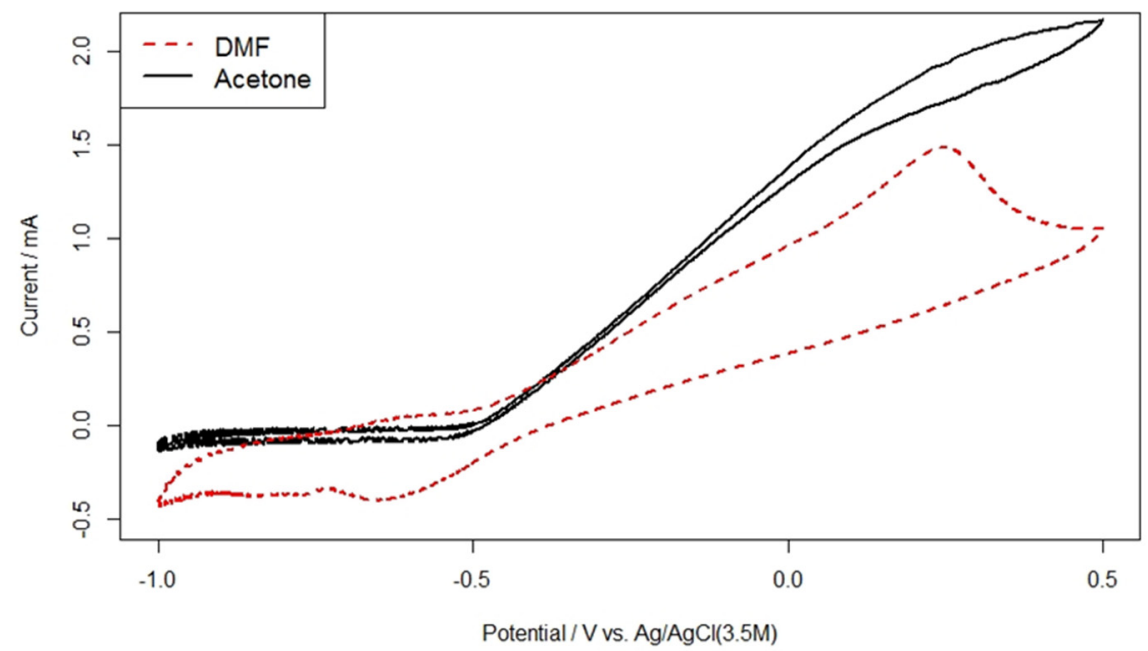

Figure 5. Cyclic voltammograms recorded under turnover conditions (scan rate of $0.1 \mathrm{mV} \cdot \mathrm{s}^{-1}$ ). The control electrode produced a negligible current and is not presented here.

\subsection{Microbial Community Analysis}

To gain a deeper insight into the impact that the activation procedures have on the microbial communities that thrive on the surface of the electrodes, the taxonomic composition of the anodic biofilms was analyzed (Figure 6). The genus Geobacter, a well-known exoelectrogen [20], was found in all three biofilms. Its relative abundance was much higher in the biofilms of the acetone- and DMF-activated electrodes compared to the control (control $4.9 \%$, DMF $33.4 \%$, acetone $52 \%$ ). Thus, the activation procedures of the PLA/graphene electrodes seem to trigger a selection process in which diversity (in terms of the number of taxa) is lost in favor of a greater richness in the electroactive genera. This might explain (at least in part) the improved bioelectrochemical performance of acetone and DMF electrodes.

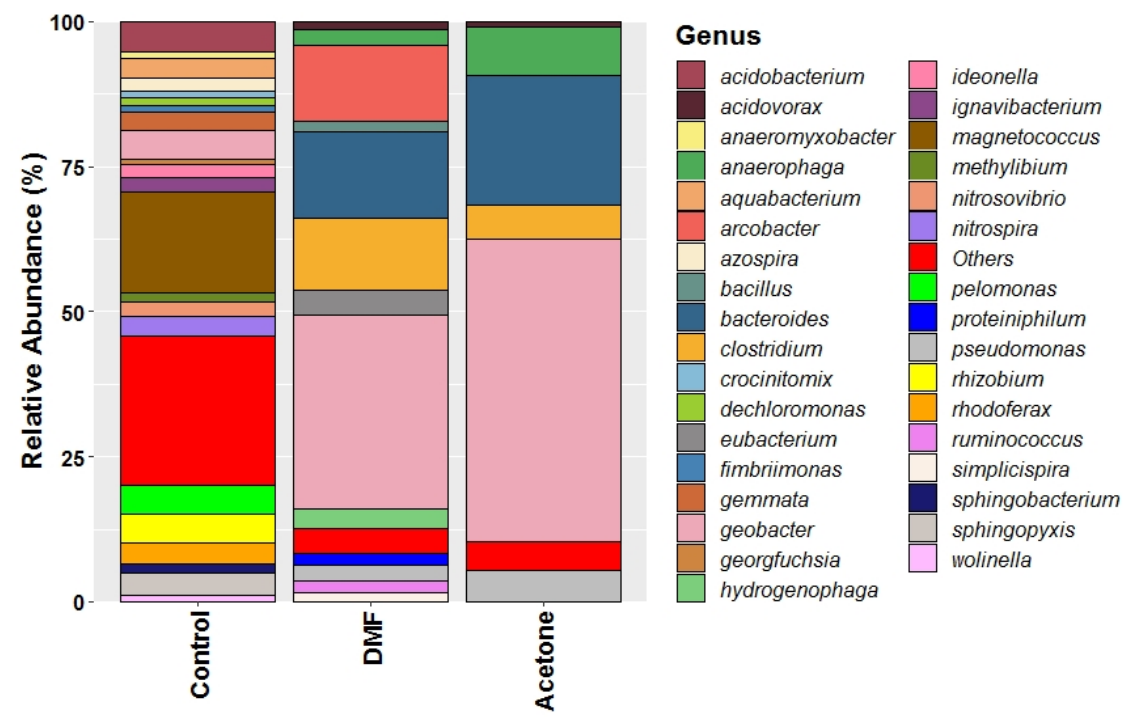

Figure 6. Taxonomic classification at genus level for the three samples. The genera represented by less than $1 \%$ of relative abundance have been grouped in "others".

\section{Conclusions}

This study demonstrates the suitability of PLA/graphene as an electrode material for METs. Results revealed that the PLA/graphene 3D-printed electrodes require previous activation to improve their electrochemical activity. Among the procedures of activation, DMF and acetone treatments showed comparable performance. The analysis of microbial communities using the material as bioanode showed a selective enrichment in the genus 
Geobacter, a well-known exoelectrogen, in the electrodes treated with DMF and acetone. The maximum current density reached was approximately $5 \mathrm{Am}^{-2}$, enabling the PLA/graphene to be considered as a promising material for innovative electrode design, opening new application possibilities for METs.

Supplementary Materials: The following supporting information can be downloaded at: https: / / www.mdpi.com/article/10.3390/app12010275/s1, Figure S1. Current density profiles of two successive cycles at the end of a 60 days period that allowed for the development of a stable biofilm; Table S1: Fitted parameters to EC 1 (DMF and acetone electrodes); Table S2: Fitted parameters to EC 2 (control and electrochemical-treated electrodes); Figure S2. Equivalent circuits for abiotic electrode essays' modellization. (1) DMF and acetone (2) Control and electrochemical treatment.

Author Contributions: R.M.A.: conceptualization, methodology, original draft preparation. I.S.M.: review and editing. A.E.: supervision, data interpretation, writing-reviewing and editing. A.M.: supervision, reviewing, funding acquisition. All authors have read and agreed to the published version of the manuscript.

Funding: This research was funded by "Ministerio de Economía y Competitividad (Gobierno de España) grant number: PID2020-115948RB-I00 (MINECO/FEDER, EU) and “Ente Regional de la Energía de Castilla y Leon", grant number: EREN_2019_L3_ULE.

Institutional Review Board Statement: Not applicable.

Informed Consent Statement: Not applicable.

Data Availability Statement: The raw/processed data required to reproduce these findings cannot be shared at this time as the data also form part of an ongoing study.

Conflicts of Interest: The authors declare that they have no known competing financial interest or personal relationship that could have appeared to influence the work reported in this paper.

\section{References}

1. Schröder, U.; Harnisch, F.; Angenent, L.T. Microbial Electrochemistry and Technology: Terminology and Classification. Energy Environ. Sci. 2015, 8, 513-519. [CrossRef]

2. Alonso, R.M.; San-Martín, M.I.; Sotres, A.; Escapa, A. Graphene Oxide Electrodeposited Electrode Enhances Start-up and Selective Enrichment of Exoelectrogens in Bioelectrochemical Systems. Sci. Rep. 2017, 7, 1-10. [CrossRef] [PubMed]

3. Zhang, P.; Liu, J.; Qu, Y.; Li, D.; He, W.; Feng, Y. Nanomaterials for Facilitating Microbial Extracellular Electron Transfer: Recent Progress and Challenges. Bioelectrochemistry 2018, 123, 190-200. [CrossRef] [PubMed]

4. Kaur, R.; Marwaha, A.; Chhabra, V.A.; Kim, K.-H.; Tripathi, S.K. Recent Developments on Functional Nanomaterial-Based Electrodes for Microbial Fuel Cells. Renew. Sustain. Energy Rev. 2020, 119, 109551. [CrossRef]

5. San-Martín, M.I.; Escapa, A.; Alonso, R.M.; Canle, M.; Morán, A. Degradation of 2-Mercaptobenzothizaole in Microbial Electrolysis Cells: Intermediates, Toxicity, and Microbial Communities. Sci. Total Environ. 2020, 733, 139155. [CrossRef] [PubMed]

6. Strack, G. Additive Manufacturing Approaches for Biological Power Generation. Curr. Opin. Electrochem. 2019, 17, 167-173. [CrossRef]

7. Chiranjeevi, P.; Patil, S.A. Strategies for Improving the Electroactivity and Specific Metabolic Functionality of Microorganisms for Various Microbial Electrochemical Technologies. Biotechnol. Adv. 2019, 39, 107468. [CrossRef] [PubMed]

8. O'Neil, G.D.; Ahmed, S.; Halloran, K.; Janusz, J.N.; Rodríguez, A.; Terrero Rodríguez, I.M. Single-Step Fabrication of Electrochemical Flow Cells Utilizing Multi-Material 3D Printing. Electrochem. Commun. 2019, 99, 56-60. [CrossRef]

9. Kumar, K.P.A.; Ghosh, K.; Alduhaish, O.; Pumera, M. Metal-Plated 3D-Printed Electrode for Electrochemical Detection of Carbohydrates. Electrochem. Commun. 2020, 120, 106827. [CrossRef]

10. Redondo, E.; Pumera, M. MXene-Functionalised 3D-Printed Electrodes for Electrochemical Capacitors. Electrochem. Commun. 2021, 124, 106920. [CrossRef]

11. Zhang, J.; Li, X.L.; Fan, S.; Huang, S.; Yan, D.; Liu, L.; Valdivia y Alvarado, P.; Yang, H.Y. 3D-Printed Functional Electrodes towards Zn-Air Batteries. Mater. Today Energy 2020, 16, 100407. [CrossRef]

12. Gusmão, R.; Browne, M.P.; Sofer, Z.; Pumera, M. The Capacitance and Electron Transfer of 3D-Printed Graphene Electrodes Are Dramatically Influenced by the Type of Solvent Used for Pre-Treatment. Electrochem. Commun. 2019, 102, 83-88. [CrossRef]

13. Browne, M.P.; Novotný, F.; Sofer, Z.; Pumera, M. 3D Printed Graphene Electrodes' Electrochemical Activation. ACS Appl. Mater. Interfaces 2018, 10, 40294-40301. [CrossRef] [PubMed]

14. Marshall, C.W.; Ross, D.E.; Fichot, E.B.; Norman, R.S.; May, H.D. Electrosynthesis of Commodity Chemicals by an Autotrophic Microbial Community. Appl. Environ. Microbiol. 2012, 78, 8412-8420. [CrossRef] [PubMed] 
15. Yuan, H.-R.; Deng, L.-F.; Qian, X.; Wang, L.-F.; Li, D.-N.; Chen, Y.; Yuan, Y. Significant Enhancement of Electron Transfer from Shewanella Oneidensis Using a Porous N-Doped Carbon Cloth in a Bioelectrochemical System. Sci. Total Environ. 2019, 665, 882-889. [CrossRef] [PubMed]

16. Mateos, R.; Alonso, R.M.; Escapa, A.; Morán, A. Methodology for Fast and Facile Characterisation of Carbon-Based Electrodes Focused on Bioelectrochemical Systems Development and Scale Up. Materials 2017, 10, 79. [CrossRef] [PubMed]

17. Mei, B.A.; Lau, J.; Lin, T.; Tolbert, S.H.; Dunn, B.S.; Pilon, L. Physical Interpretations of Electrochemical Impedance Spectroscopy of Redox Active Electrodes for Electrical Energy Storage. J. Phys. Chem. C 2018, 122, 24499-24511. [CrossRef]

18. Yoho, R.A.; Popat, S.C.; Rago, L.; Guisasola, A.; Torres, C.I. Anode Biofilms of Geoalkalibacter Ferrihydriticus Exhibit Electrochemical Signatures of Multiple Electron Transport Pathways. Langmuir 2015, 31, 12552-12559. [CrossRef]

19. Liu, Y.; Harnisch, F.; Fricke, K.; Sietmann, R.; Schröder, U. Improvement of the Anodic Bioelectrocatalytic Activity of Mixed Culture Biofilms by a Simple Consecutive Electrochemical Selection Procedure. Biosens. Bioelectron. 2008, 24, 1006-1011. [CrossRef]

20. Reguera, G.; Kashefi, K. The Electrifying Physiology of Geobacter Bacteria, 30 Years On. Adv. Microb. Physiol. $2019,74,1-96$.

21. Marsili, E.; Rollefson, J.B.; Baron, D.B.; Hozalski, R.M.; Bond, D.R. Microbial Biofilm Voltammetry: Direct Electrochemical Characterization of Catalytic Electrode-Attached Biofilms. Appl. Environ. Microbiol. 2008, 74, 7329-7337. [CrossRef]

22. Liu, Y.; Deng, D.; Lan, X. A Highly Efficient Mixed-Culture Biofilm as Anodic Catalyst and Insights into Its Enhancement through Electrochemistry by Comparison with G. Sulfurreducens. Electrochim. Acta 2015, 155, 327-334. [CrossRef]

23. Esteve-Núñez, A.; Rothermich, M.; Sharma, M.; Lovley, D. Growth of Geobacter Sulfurreducens under Nutrient-Limiting Conditions in Continuous Culture. Environ. Microbiol. 2005, 7, 641-648. [CrossRef] [PubMed]

24. Popat, S.C.; Torres, C.I. Critical Transport Rates That Limit the Performance of Microbial Electrochemistry Technologies. Bioresour. Technol. 2016, 215, 265-273. [CrossRef] [PubMed] 